Article

\title{
Research on Semisolid Microstructural Evolution of 2024 Aluminum Alloy Prepared by Powder Thixoforming
}

\section{Pubo Li ${ }^{1}$, Tijun Chen ${ }^{1, *}$, Suqing Zhang $^{1}$ and Renguo Guan ${ }^{2}$}

1 State Key Laboratory of Advanced Processing and Recycling of Nonferrous Metals, Lanzhou University of Technology, Lanzhou 730050, China; E-Mails: lipubogs@163.com (P.L.); zhangsuqing1985@163.com (S.Z.)

2 School of Materials and Metallurgy, Northeastern University, Shenyang 110004, China; E-Mail: guanrg@smm.neu.edu.cn

* Author to whom correspondence should be addressed; E-Mail: chentj@lut.cn; Tel.: +86-931-297-6573; Fax: +86-931-297-6578.

Academic Editor: E. W. Jarfors

Received: 1 February 2015 / Accepted: 27 March 2015 / Published: 3 April 2015

\begin{abstract}
A novel method, powder thixoforming, for net-shape forming of the particle-reinforced Aluminum matrix composites in semi-solid state has been proposed based on powder metallurgy combining with thixoforming technology. The microstructural evolution and phase transformations have been investigated during partial remelting of the 2024 bulk alloy, prepared by cold pressing of atomized alloy powders to clarify the mechanisms of how the consolidated powders evolve into small and spheroidal primary particles available for thixoforming. The effect of heating temperature on the resulting semisolid microstructure has also been discussed. The results indicate that the microstructural evolution includes three stages - the initial rapid coarsening of the fine grains within the powders, the formation of continuous liquid layer on the primary particle surface (the original powder), and the final coarsening - that result from the phase transformations of $\theta \rightarrow \alpha, \alpha \rightarrow \mathrm{L}$, and $\alpha \rightarrow \mathrm{L}$ and $\mathrm{L} \rightarrow \alpha$, respectively. The coarsening rate of the primary particles is low, and one original powder always evolves into one spheroidal particle with a continuous liquid layer surface. Properly raising the heating temperature is beneficial for obtaining an ideal semisolid microstructure.
\end{abstract}

Keywords: powder thixoforming; cold pressing; coarsening rate; spheroidal particles 


\section{Introduction}

$\mathrm{SiC}$ particle $\left(\mathrm{SiC}_{\mathrm{p}}\right)$-reinforced Aluminum matrix composites $\left(\mathrm{SiC}_{\mathrm{p}} / \mathrm{Al}\right)$ have been developed successfully over the past few decades, owing to their excellent properties such as light weight, high temperature strength, good wear resistance, and a low thermal expansion coefficient [1-5]. The existing fabrication techniques include powder metallurgy (PM), squeeze casting, pressure or pressureless infiltration, and spray forming [2]. It is known that the PM process is particularly popular due to the uniform distribution of reinforcements and flexible constituent design [6,7]. However, the PM-processed products always have a very high cost due to the complex processing procedures, and their microstructures are relatively loose due to difficultly eliminated pores, which seriously limit its wider application [6,8]. In addition, components with complex shape and/or large size are also very difficult to fabricate using this technology. However, thixoforming can significantly decrease or even eliminate porosities, and thus can produce components with compact microstructures. Furthermore, the mechanical properties of the produced components can be significantly improved compared to fully liquid casting [9]. In addition, this technology is also very suitable for producing large-sized components with complex shape [10]. The key procedure for the thixoforming technology is the production of a non-dendritic microstructure with fine globular grains, suspended in liquid phase [9]. To reach the desirable microstructure, the starting materials must be specially treated prior to partial remelting, i.e., pre-deformed, refined, and stirred in the semi-solid state or during solidification $[9,11,12]$. If the bulk alloy prepared by pressing of the small and spheroidal alloy powders can be used as the feedstock of thixoforming, a new approach to producing a non-dendritic semisolid microstructure available for thixoforming will be developed. Therefore, combining the advantages of both PM and thixoforming technologies, a new technology that can prepare and form $\mathrm{SiC}_{\mathrm{p}} / \mathrm{Al}$ matrix composite, powder thixoforming, has been proposed. The mixing and cold pressing steps of PM are applied to prepare the start ingots with uniform distribution of reinforcing particles in the matrix. Then the ingots are partially remelted and thixoformed.

At present, the most similar technologies to powder thixoforming are semisolid powder processing [13] and pseudo-semisolid thixoforming $[14,15]$. The former has bad thixoformability due to the high solid fraction (>90\%) and mainly focuses on the effects of SiC volume fraction and particle size, and forming pressure on the mechanical properties. The latter's forming temperature is the pseudo-semi-solid temperature at which the matrix $\left(\mathrm{SiC}_{\mathrm{p}}\right.$ or $\left.\mathrm{Al}_{2} \mathrm{O}_{3} \mathrm{p}\right)$ is in solid state and the metal $(\mathrm{Al})$ is in liquid state, and the solid fraction is also very high $(60 \%-70 \%)$. Unfortunately, existing investigations on the proposed powder thixoforming have not been found.

It is well known that the microstructural evolution during partial remelting is another key topic for thixoforming because this process will have a significant influence on the resultant semisolid microstructure. However, existing references about how the powders evolve into primary particles in the semisolid microstructure have not addressed this problem. In addition, the microstructural evolution essentially results from phase transformations occurring during partial remelting, and research on the phase transformations is capable of providing some useful information toward clarify the microstructural evolution mechanisms. However, the existing investigations have not involved this aspect.

Therefore, the microstructural evolution of 2024 bulk alloy during partial remelting was first verified in order to preferably clarify that of the $\mathrm{SiC}_{\mathrm{p}} / 2024$ Al-based composite. Simultaneously, the phase 
transformations occurring during partial remelting and the effect of heating temperature on the semisolid microstructure have also been discussed.

\section{Experimental Section}

\subsection{Material}

The material used is 2024 Aluminum alloy powder $\left(\mathrm{Al}_{\mathrm{p}}\right)$ prepared by atomization (Zhejiang Bainianyin Industry \& Trade Co., Ltd., Yongkang, Zhejiang, China), and has an average particle size of $20 \mu \mathrm{m}$ and a spherical morphology (Figure 1). Its actual composition is $\mathrm{Al}-4.22 \mathrm{Cu}-1.35 \mathrm{Mg}-0.5 \mathrm{Si}-0.5 \mathrm{Fe}-0.5 \mathrm{Mn}$ (in $w t \%$ ). To confirm the partial remelting temperature, this alloy was analyzed by a Pyris Diamond TG/DTA differential thermal analyzer (DTA; NETZSCH, Bavaria, Germany). As shown in Figure 2, its solidification range is $498-663.7^{\circ} \mathrm{C}$.
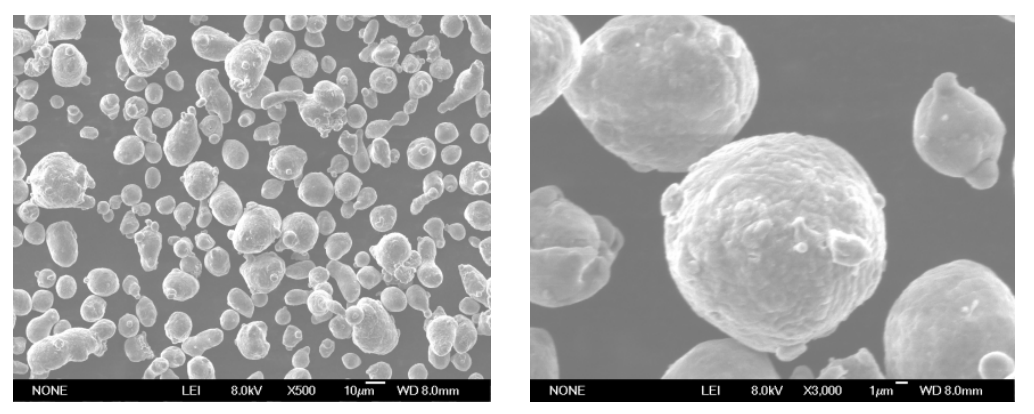

Figure 1. SEM micrographs of the as-received 2024 alloy powders.

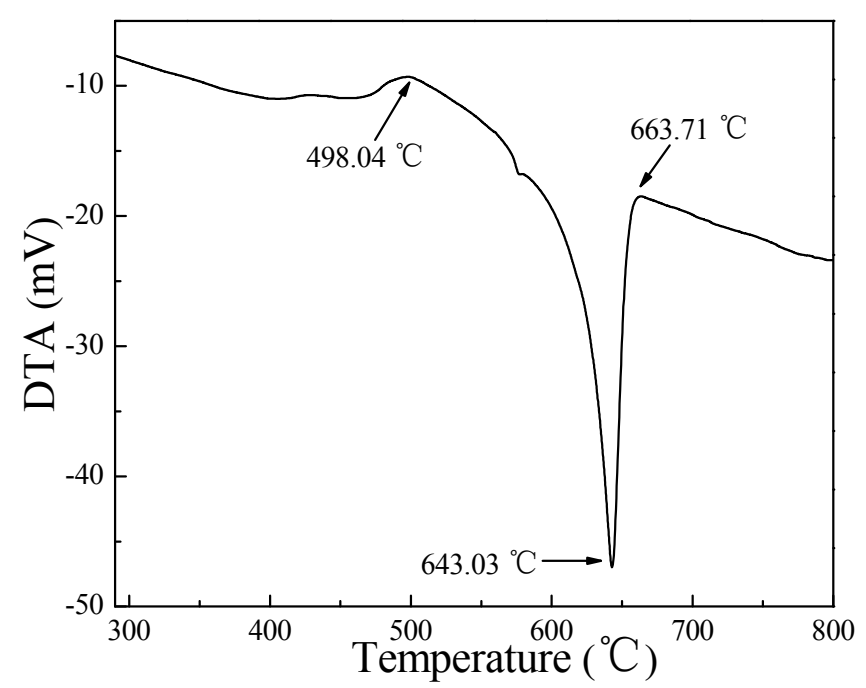

Figure 2. Differential thermal analyzer (DTA) curve of the 2024 alloy powders.

\subsection{Experiments}

Twenty grams of $\mathrm{Al}_{\mathrm{p}}$ were uniaxially cold-compacted at $300 \mathrm{MPa}$ pressure for $5 \mathrm{~min}$ to produce green billets with $30 \mathrm{~mm}$ in diameter and $7 \mathrm{~mm}$ in height. Repeating the experimental procedures, some billets were obtained. Then some of them were heated at a semisolid temperature of $635^{\circ} \mathrm{C}$ for different times (0-60 min) to study the microstructural evolution of the bulk alloy during partial remelting. The other 
billets were heated for $30 \mathrm{~min}$ at different temperatures $\left(625,630\right.$, and $\left.640{ }^{\circ} \mathrm{C}\right)$ to investigate the influence of heating temperature on semisolid microstructure. To examine the billets' temperature variation during partial remelting, one thermocouple was inserted into a hole in the center of one billet. The billets are composed of alloy powders, so it can be expected that clarifying the microstructural evolution of a single $\mathrm{Al}_{\mathrm{p}}$ is very helpful to study that of the billet. For this purpose, some powders were heated for different durations $(0-30 \mathrm{~min})$ at a temperature of $635^{\circ} \mathrm{C}$.

\subsection{Metallographic Characterization}

All of the heated billets were quickly quenched in a Bi-based alloy melted at about $45{ }^{\circ} \mathrm{C}$. Each of the resultant billets was cut along the radial direction into two specimens. Then a cross section of one specimen was finished and polished by standard metallographic techniques, followed by etching using Keller's etchant (Yantai Shuangshuang Chemical Co., Ltd., Haiyang, Shandong, China). The heated powders were water-quenched and then prepared into small specimens together with epoxy resin, and finally they were also prepared into standard metallographic specimens using the same procedures as the quenched billet specimens. All of the specimens were observed on a scanning electron microscope (SEM; FEI, Hillsboro, OR, USA) or/and an optical microscope (OM; Nikon Instruments, Shanghai, China), and some of the billet specimens were examined by energy dispersive spectrometer (EDS; FEI, Hillsboro, OR, USA) on the SEM. To quantitatively examine the liquid fraction and the primary particle size, the related OM images were analyzed by Image-Pro Plus software (Media Cybernetics Company, Silver Spring, MD, USA). At least three typical OM images with magnification of 500 times were examined. In order to illustrate the microstructural evolution, an X-ray diffractometer (XRD; Rigaku, Tokyo, Japan) was used to verify the phase constituents of the 2024 bulk alloy heated at $635{ }^{\circ} \mathrm{C}$ for different durations in order to deduce the phase transformations occurring during partial remelting. To verify the interactions between the powders or particles during partial remelting, such as if mergence occurs, and then further clarify the coarsening mechanisms of the primary particles in semisolid microstructure, the other billet specimens were machined into tensile bars. Tensile tests were carried out on a universal material testing machine (Jinan HengXu Testing Machine Technology Co., Ltd., Jinan, Shandong, China) at a nominal strain rate of $1 \mathrm{~mm} / \mathrm{min}$. The fracture surfaces were observed on the SEM.

\section{Results and Discussion}

\subsection{Microstructural Evolution of the Alloy Powders during Partial Remelting}

Figure 3 presents the microstructures of the alloy powders heated at $635{ }^{\circ} \mathrm{C}$ for different durations. It shows that the original microstructure of a powder consisted of fine $\alpha$ - $\mathrm{Al}$ grains and intergranular eutectics between the grains (shown by arrows in Figure 3a). The difference between grain boundaries and grain interior within powder is also found in $7075 \mathrm{Al}$ powder $[16,17]$. The amount of the eutectics obviously decreases during the heating from $0 \mathrm{~min}$ to $1 \mathrm{~min}$ (comparing Figure $3 \mathrm{a}, \mathrm{b}$ ). The original powders (including many fine $\alpha$ grains) become compact particles without grain boundaries (one powder only contains one grain). Simultaneously, some white particles and globular holes appear (Figure $3 b$ ). 

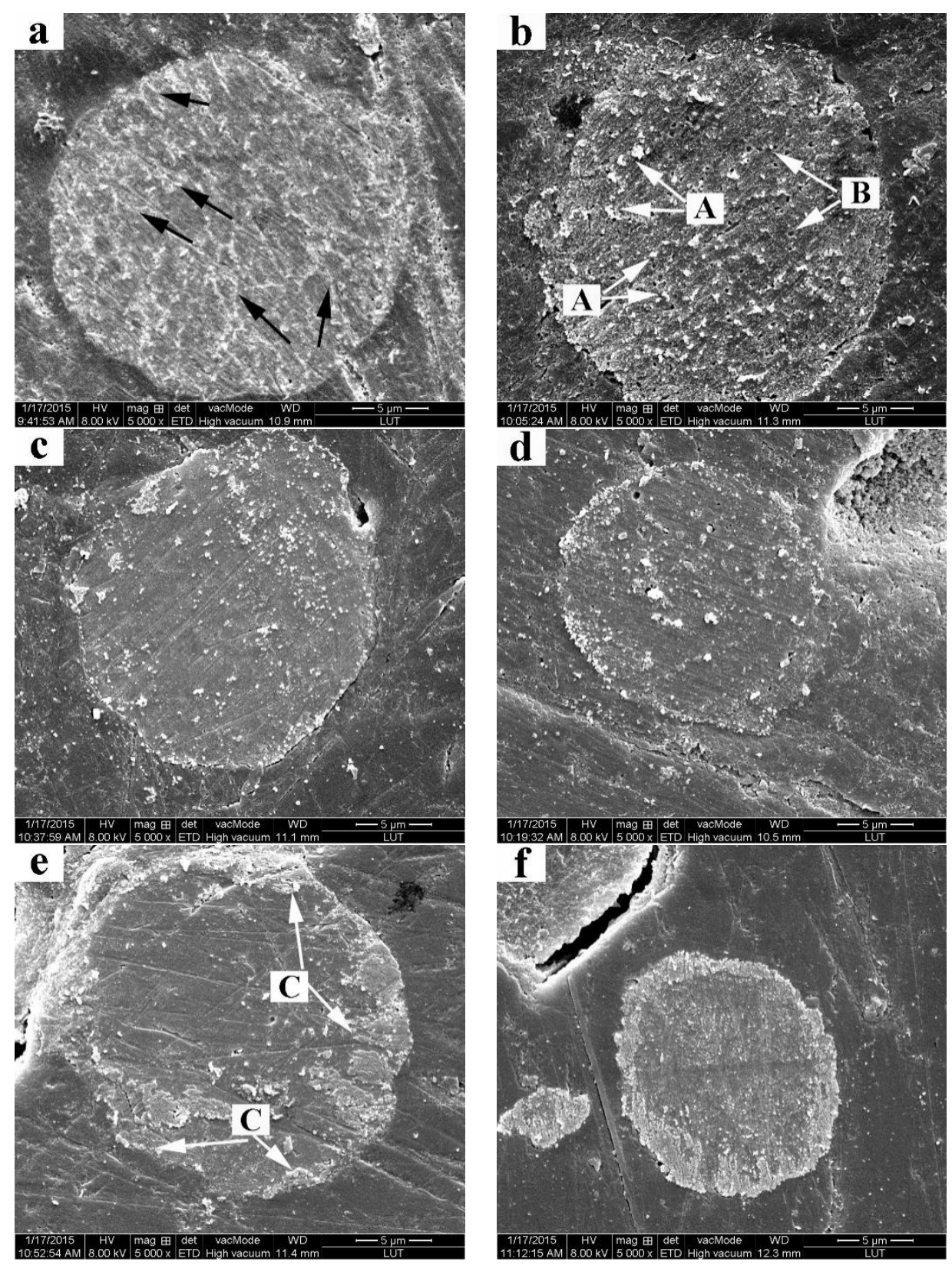

Figure 3. Micrographs of the alloy powders heated at $635^{\circ} \mathrm{C}$ for different durations and then water-quenched. (a) $0 \mathrm{~min}$; (b) $1 \mathrm{~min}$; (c) $2 \mathrm{~min}$; (d) $3 \mathrm{~min}$; (e) $10 \mathrm{~min}$; (f) $30 \mathrm{~min}$.

The $\mathrm{Al}-4 \mathrm{Cu}-1.3 \mathrm{Mg}(\mathrm{wt} \%)$ alloy is consisted three phases - $\alpha-\mathrm{Al}, \theta-\mathrm{CuAl}_{2}$, and $\mathrm{S}-\mathrm{Al}_{2} \mathrm{CuMg}$ [18]. However, because the $\mathrm{S}$ phase within this $\mathrm{Al}_{\mathrm{p}}$ is very small, the XRD can barely detect it (Figure 4). Therefore, it can be deemed that the eutectics contain an $\theta$ phase and $\alpha$-Al phase in this paper. According to the binary $\mathrm{Al}-\mathrm{Cu}$ phase diagram [19], the solubility of $\mathrm{Cu}$ in the primary $\alpha$-Al phase increases and the binary $\mathrm{Al}-4 \mathrm{Cu}$ will experience a single $\alpha-\mathrm{Al}$ phase interval (only considering the two main elements, $\mathrm{Al}$ and $\mathrm{Cu}$ ) during reheating. So the eutectics should dissolve towards the primary $\alpha$ phase as the temperature rises, resulting in the decrease of the eutectic phases. This phenomenon is also found in other as-casting materials [20,21]. Most of the eutectics between the grains have dissolved or even disappeared because the eutectic size in the interdendritic zones is smaller. Based on this standpoint, it can be supposed that the disappearance of the interdendritic eutectics must result in the disappearance of grain boundaries, and then result in the coarsening of the fine $\alpha$-Al grains through mergence. The 
original powders change into compact particles without grain boundaries. However, some small particles also appear when heated for 1 min (marked by the A arrows in Figure 3b). It can be expected that the temperature rise in the powders should be very fast and the temperature will reach and exceed the eutectic reaction temperature in a short time. That is, there is not enough time for the complete dissolution of eutectics. Then the residual interdendritic eutectics melt and become a liquid phase. From the spherical morphology of the white particles in Figure 3b, they should be liquid pools. The spherical liquid pools within the primary solid phase are also found in AZ91HP magnesium composites produced by the rotating cylinder method [22]. However, some holes inside the powders are also liquid phase due to their etching during the stage of preparing metallographic samples (marked by B in Figure 3b). Although the eutectics have not completely dissolved when heated for $1 \mathrm{~min}$, the grain boundaries have already disappeared. Thus, grain coarsening is the main phenomenon during the period $0-1 \mathrm{~min}$.

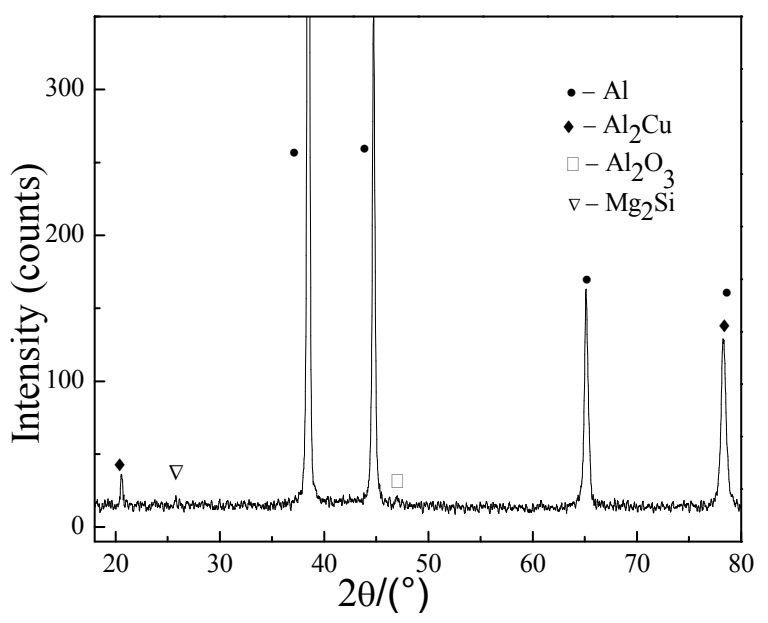

Figure 4. XRD spectrum of the 2024 Aluminum alloy.

As the reheating increases from $1 \mathrm{~min}$ to $10 \mathrm{~min}$, it can be found that the liquid phase amount within the particles decreases and that the size increases (comparing Figure 3b,e). It can be expected that the solid/liquid interfacial energy within the powders should be very high because of the large solid/liquid interfacial area (Figure 3b). To decrease the interfacial energy, the liquid pools migrate to the particles' edges, as seen in Figure 3d,e. The liquid pools also coarsen through mergence (comparing Figure 3c,d). Simultaneously, the liquid phase should be rich in solutes (such as $\mathrm{Cu}$ ) and some liquid phase dissolves towards the surrounding $\alpha \mathrm{Al}$ phase due to the increase of the $\mathrm{Cu}$ solubility in the $\alpha$ phase with the rise in heating temperature. The above reasons result in the reduction of the liquid pool's amount and an increase of the liquid pool's size (Figure 3e). In addition, the liquid amount around the particles obviously increases as the liquid pools within the particles decrease, and a continuous liquid layer forms around the particles when heated for 10 min (marked by $\mathrm{C}$ in Figure 3e). The reason is that the primary particles (the original powders) partially melt, driven by the requirement for increasing liquid amount due to the temperature rise. Thus the main event occurring during the period of $1-10 \mathrm{~min}$ is the variations of the liquid pools and the formation of a continuous liquid layer on the primary particle surface.

When the heating time is further prolonged, the primary particles further melt due to the further rise of the temperature, which leads the liquid amount surrounding the primary particles to continuously increase (comparing Figure 3e,f). More importantly, one powder evolves into one primary particle with 
a continuous liquid layer surface. Because the original alloy powders are quite spheroidal, the primary particles in the semisolid microstructure always remain spheroidal (Figure 3). This phenomenon is different from the microstructural evolution of the as-cast materials, which generally needs to experience the spheroidization stage to obtain spheroidal primary particles [20,21]. Therefore, the main event occurring during the period of $10-30 \mathrm{~min}$ is the further increase of the liquid amount surrounding the primary particles.

Based on the above discussion, it can be concluded that the microstructural evolution of $\mathrm{Al}_{\mathrm{p}}$ can be divided into two stages: the initial rapid coarsening of the fine grains due to the dissolution of the eutectics (0-1 min) and the formation of a continuous liquid layer on the primary particle surface, ascribed to the partial melting of the primary particles (1-30 min). One spherical powder evolves into one spheroidal primary particle with a continuous liquid layer surface.

\subsection{Microstructural Evolution of the Bulk Alloy during Partial Remelting}

Figure 5 indicates the microstructures of the 2024 bulk alloy heated at the semisolid temperature of $635{ }^{\circ} \mathrm{C}$ for different durations. It shows that the eutectics (shown by arrows in Figure 5a) gradually decrease and the grain boundaries within powders disappear during the heating period 0-3 min (Figure $5 \mathrm{a}-\mathrm{d}$ ). As the reheating increases from $3 \mathrm{~min}$ to $10 \mathrm{~min}$, the liquid amount around the particles obviously increases, accompanied by the decrease of the liquid pools within the particles (Figure 5d-f). The above phenomena are basically consistent with the processes that the powders have experienced in this heating stage of $0-10 \mathrm{~min}$.

For the same reasons as the powders, a continuous decrease in the eutectic amount and coarsening of the grains have occurred during the early heating stage 0-3 min (Figure 5a-d). The liquid phase within the particles appears after being heated for 3 min (marked by A in Figure 5d). Figure 6 shows that the heating rate of the bulk alloy during the $0-3 \mathrm{~min}$ stage is rapid, so the eutectics have no enough time to completely dissolve into the primary $\alpha$ phase when the specimen's temperature reaches the eutectic reaction temperature. The residual eutectic phases then melt to form liquid phase. However, some holes inside the particles also appear (marked by B in Figure 5d). As discussed above, the holes are also the liquid phase. It is just for this reason that the arrows B in Figure $5 \mathrm{c}$ and e represent the residual $\theta$ phase and liquid phase, respectively. The microstructure of the bulk alloy heated for 3 min - compact particles without grain boundaries - is similar to that of the powders heated for $1 \mathrm{~min}$, but the liquid phase amount in the bulk alloy microstructure is obviously less than that of the powders (comparing Figures $3 \mathrm{~b}$ and 5d). The interdendritic eutectics only decrease when heated for 1 min (comparing Figure 5a,b). The above phenomena should be attributed to the reason that the heating rate of the bulk alloy is relatively slower than that of the powders. Namely, the microstructural evolution rate of the bulk alloy lags behind that of the powders during the initial period of 0-3 min. Thus grain coarsening is the main phenomenon occurring in this period. 

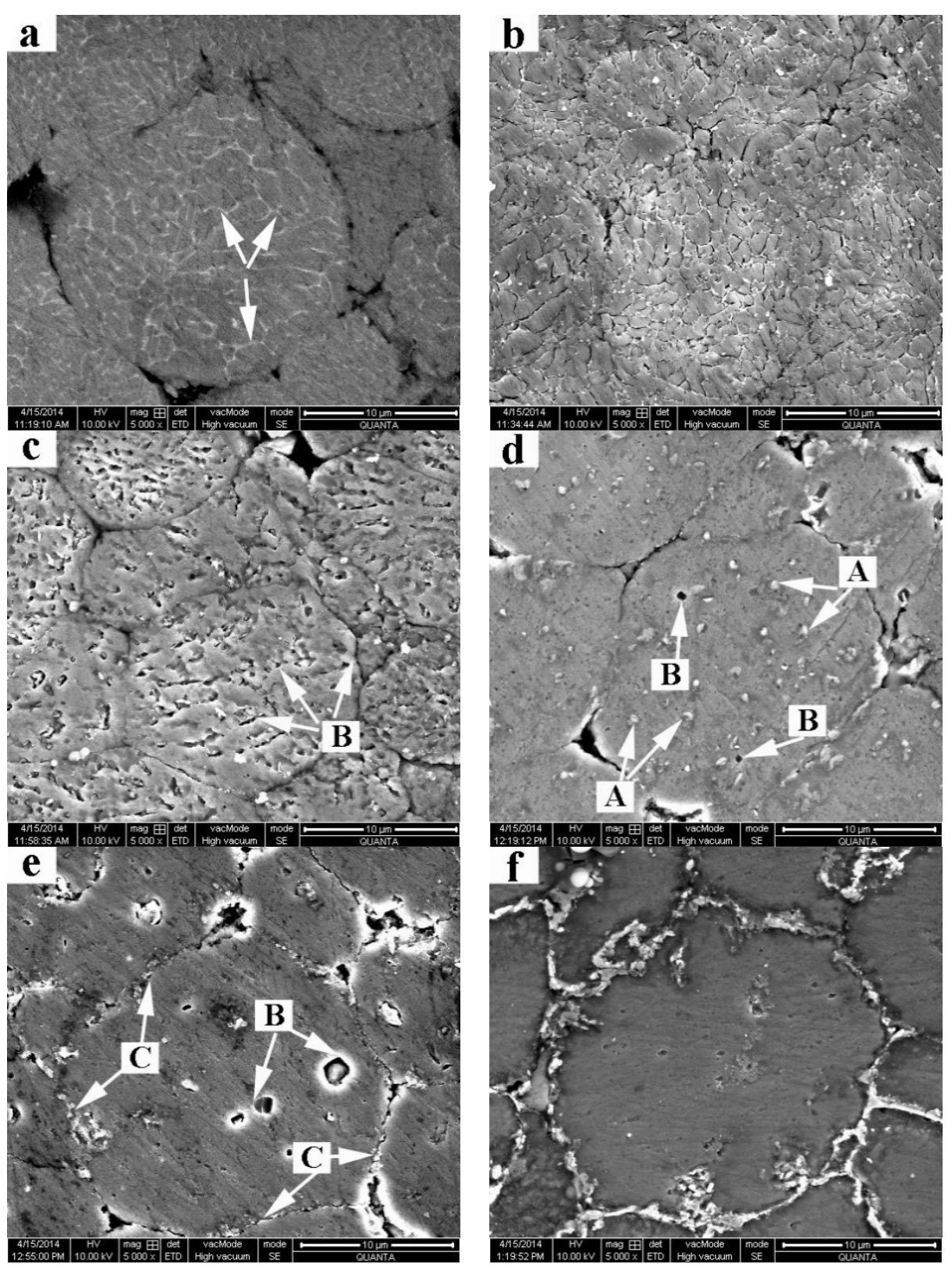

Figure 5. Micrographs of the 2024 bulk alloy heated at $635{ }^{\circ} \mathrm{C}$ for different durations and then quenched. (a) $0 \mathrm{~min}$; (b) $1 \mathrm{~min}$; (c) $2 \mathrm{~min}$; (d) $3 \mathrm{~min}$; (e) $5 \mathrm{~min}$; (f) $10 \mathrm{~min}$.

As the heating time is further prolonged, the liquid phase gradually distributes between the neighboring particles as that within the particles decreases (Figure 5d-f). As discussed above, the powders partially melt, driven by increasing liquid amount due to the temperature rise. Figure 5e shows that some sites melt to form discontinuous liquid layers or small-sized liquid pools between the primary particles (marked by $\mathrm{C}$ in Figure 5e). A continuous liquid layer forms around the primary particles when the particles further melt (Figure 5f), which is similar to the phenomenon that the structure separation has completed in the as-casting materials during partial remelting [20,21]. The liquid pools within particles also generate dissolution towards the $\alpha$ phase, migration to the particles' boundaries, and coalescence to decrease the solid/liquid interfacial energy (comparing Figure 5d,f). Therefore, the main phenomenon occurring during the $3-10 \mathrm{~min}$ period is basically similar to that of the powders when heated for $1 \mathrm{~min}$. 


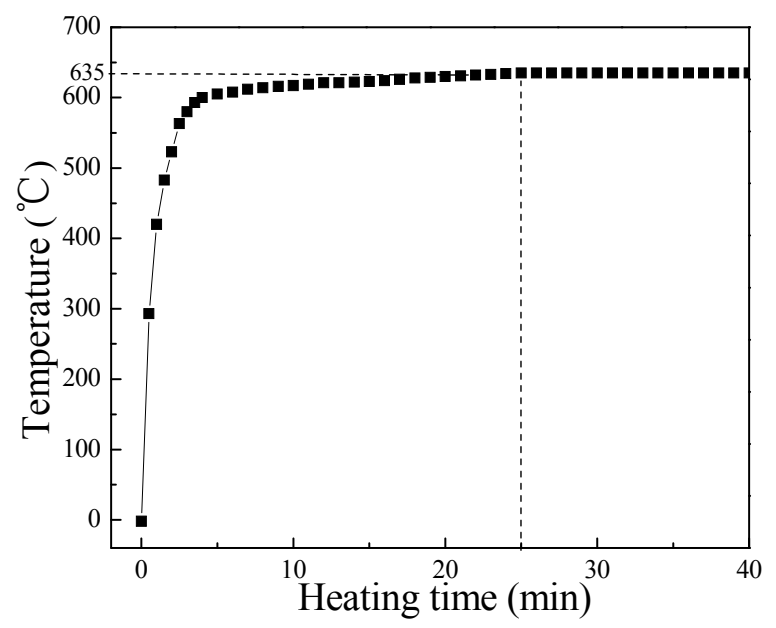

Figure 6. Temperature variation in the specimen with heating time.

Figure 7 shows the microstructures of the 2024 bulk alloy heated at $635{ }^{\circ} \mathrm{C}$ for over $10 \mathrm{~min}$. It can be seen that the microstructures always consist of large and small particles during the heating period 10-60 min. The neighboring particles are separated by black continuous eutectics. However, the amount of the small particles increases as that of the large particles decreases when heated for 20 min (comparing Figure 7a,b). As the heating time is prolonged, it can be supposed that the liquid amount increases due to the temperature rise. The liquid phase solidifies into secondarily primary $\alpha$-Al phase during quenching. However, the solidification rate of the liquid phase is very rapid during quenching, so the secondarily solidified particles are smaller than the primary $\alpha$-Al particles anyhow. Thus it can be concluded that the relatively small particles in the quenched microstructures originate from the solidification of the liquid phase. Figure 8 shows the full-liquid microstructure when heated at $710{ }^{\circ} \mathrm{C}$ for $30 \mathrm{~min}$. It shows that this microstructure is all small particles and intergranular eutectics. The result of quantitative examination of Figure 8 shows that the particle size is close to $5 \mu \mathrm{m}$. Therefore, the particles which are less than $5 \mu \mathrm{m}$ are regarded as the liquid phase in this paper. Based on this standpoint, Figure 7a clearly shows that the liquid phase (marked by circles) distributes between the particles.
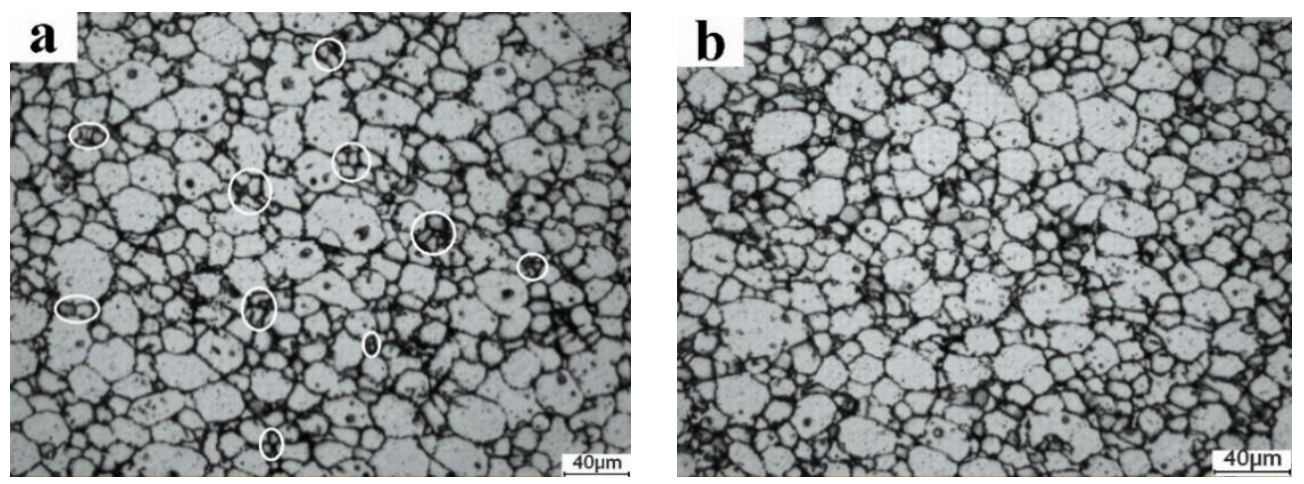

Figure 7. Cont. 


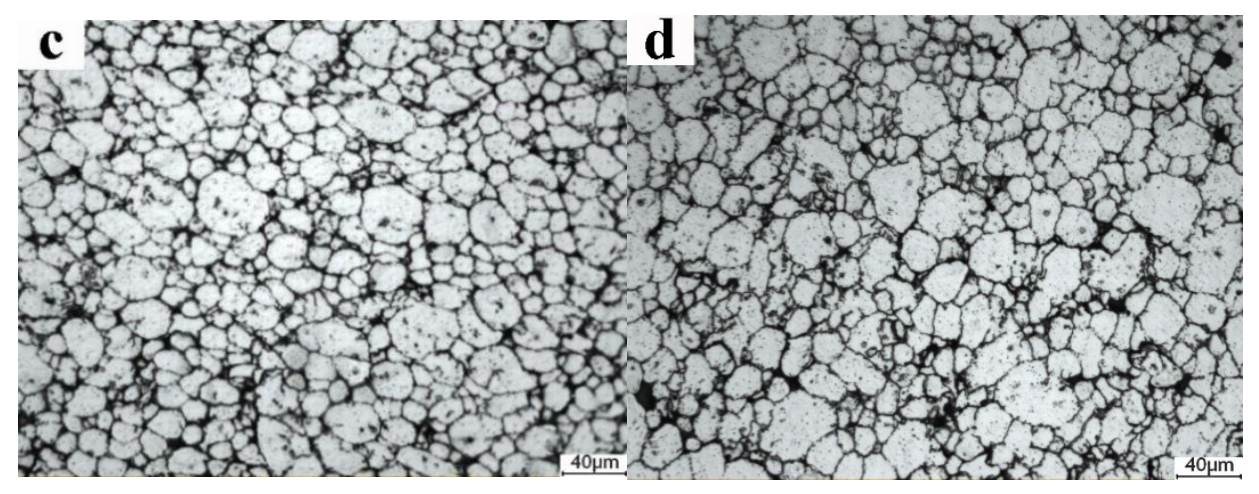

Figure 7. Micrographs of the 2024 bulk alloy heated at $635{ }^{\circ} \mathrm{C}$ for different durations and then quenched. (a) $10 \mathrm{~min}$; (b) $20 \mathrm{~min}$; (c) $30 \mathrm{~min}$; (d) $60 \mathrm{~min}$.

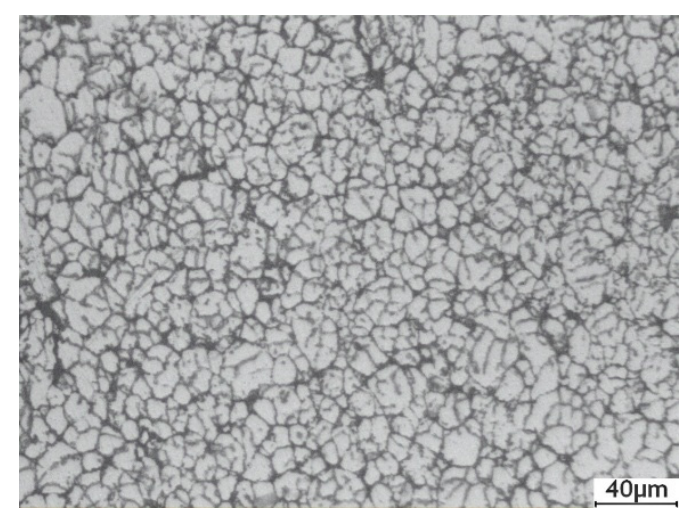

Figure 8. Micrograph of the bulk alloy heated at $710{ }^{\circ} \mathrm{C}$ for $30 \mathrm{~min}$ and then quenched.

As shown in Figure $7 \mathrm{a}-\mathrm{c}$, the liquid amount gradually increases through partial melting of the particles due to the temperature rise, and the primary particle size remains almost unchanged. Moreover, the shapes of the particles in the present microstructure are always spherical. The distance between the primary particles is small, and some of the neighboring particles are only separated by thin eutectics (Figure 7a). Under this condition, the solid/liquid interfacial energy should be very high due to the large solid/liquid interfacial area. Thus, the particles should coarsen during the subsequent heating driving by decreasing the interfacial energy. However, the coarsening does not operate during the 10-30 min period. Alumina layers have already formed on the surfaces of the alloy powders [23]. The great difference in the coefficient of thermal expansion between Aluminum and alumina will generate stress on the oxide shell during heating, leading to a dynamic oxide breakage and repair process if there is any oxygen in the atmosphere [24]. Namely, the alumina on the surfaces of the alloy powders cannot disappear as the heating proceeds, and thus the healed or original oxide can hinder the merging of the neighboring particles (Figure $7 \mathrm{a}-\mathrm{c}$ ). So it can be concluded that the low coarsening rate of the particles is due to the less active coalescence. In addition, because the as-received $\mathrm{Al}_{\mathrm{p}}$ is spherical in shape with a particle size of $20 \mu \mathrm{m}$, and the coalescence of the particles which evolve from the original powders is impossible, the microstructure does not need to experience an additional spheroidization stage to obtain the spheroidal primary particles. Thus, it is not difficult to understand the present experimental results; the primary particles are always small and spheroidal. The main event occurring during the 10-30 min period is the further increase of the liquid amount. 
Coarsening through mergence cannot be found during partial remelting (Figures 5 and 7). This can be more clearly demonstrated by the fracture surfaces of the bulk alloy heated at $635{ }^{\circ} \mathrm{C}$ for different durations (Figure 9). It shows that the plastic deformation of the powders occurs during cold pressing (shown by arrows in Figure 9a). Figure 9b shows that the powders are individual, which means that coalescence between neighboring powders is impossible during the initial heating stage of $0-3 \mathrm{~min}$ (Figure 9a,b). The appearance of sintering necks demonstrates that transformation from mechanical bonding to good metallurgical bonding among the powders occurs (marked by arrows in Figure 9b). This phenomenon is common in PM [25]. However, the mergence between particles does not accompany microstructural evolution during the 3-30 min period (Figure 9b-e). As discussed above, a continuous liquid layer on the primary particle surface gradually forms after being heated for 3 min, which can be better demonstrated by the fracture surfaces (marked by A in Figure 9c-e). In short, coarsening through mergence is impossible during partial remelting.

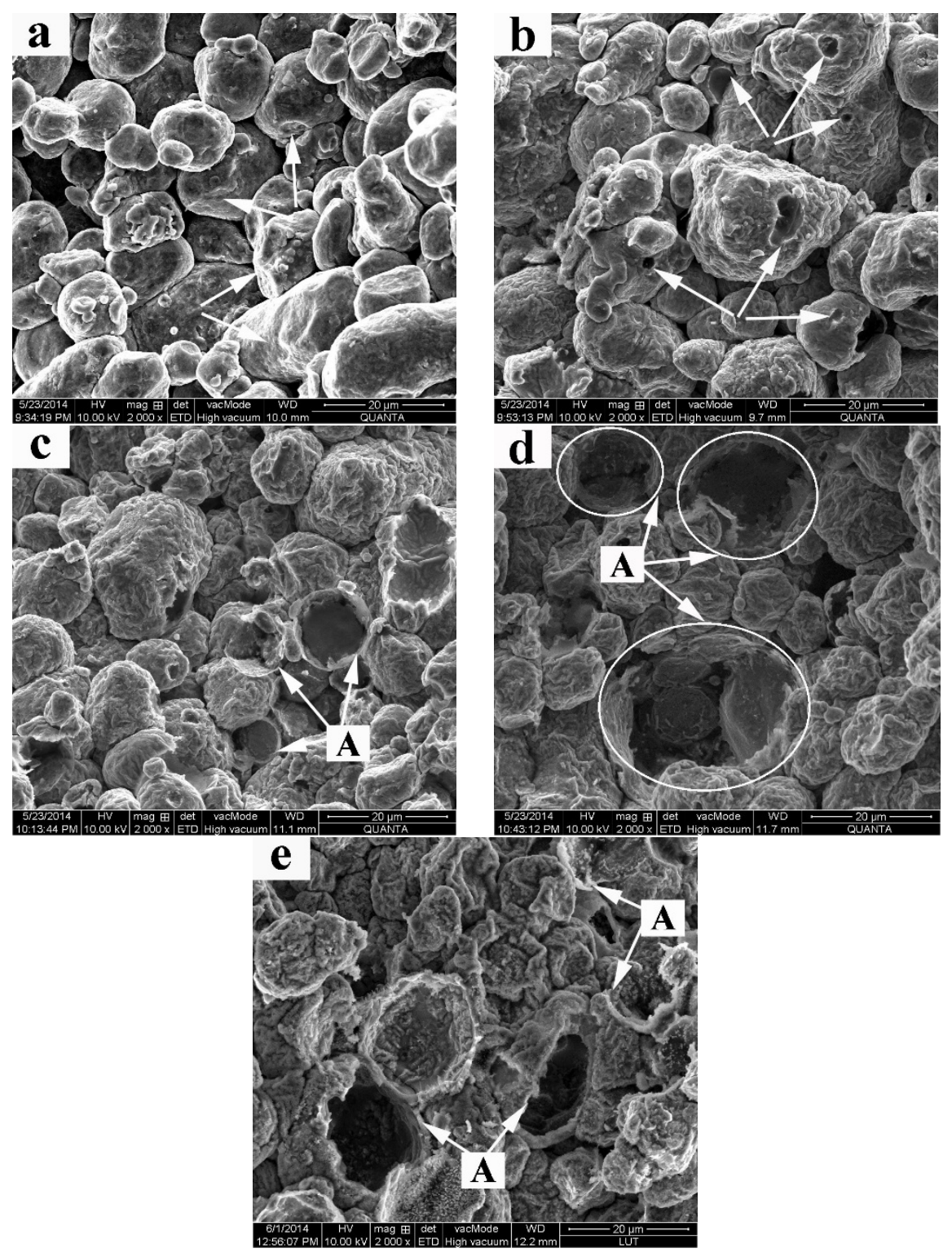

Figure 9. Fractographs of the bulk alloy heated at $635{ }^{\circ} \mathrm{C}$ for different durations and then quenched. (a) 0 min; (b) 3 min; (c) 5 min; (d) 10 min; (e) 30 min. 
The liquid amount remains almost unchanged after being heated for $30 \mathrm{~min}$ (comparing Figure 7c,d), which can be more obviously seen by the quantitative examinations shown in Figure 10. Figure 6 indicates that the specimen's temperature reaches the final equilibrium temperature of $635^{\circ} \mathrm{C}$ after being heated for $25 \mathrm{~min}$, which implies that the system reaches its solid/liquid equilibrium state and the liquid amount is basically invariable after that. This phenomenon is consistent with metallographic analysis. The particle size slightly increases as the heating time is further prolonged (Figure 10). Thus the main event occurring after heating for $30 \mathrm{~min}$ is the slight coarsening of the primary particles.

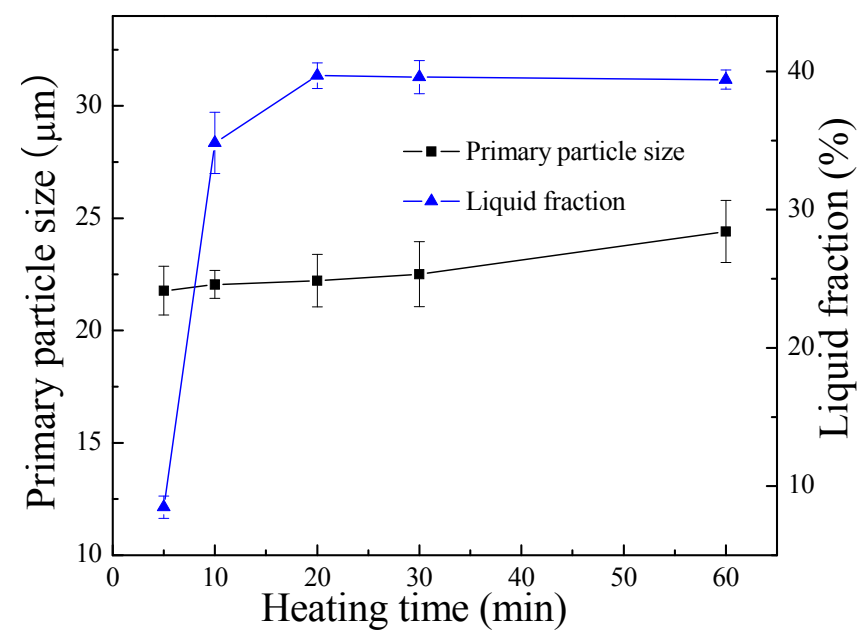

Figure 10. Variations in the primary particle size and liquid fraction of the bulk alloy with heating time after being heated for $5 \mathrm{~min}$ at $635^{\circ} \mathrm{C}$.

The coarsening mechanisms after being heated for $30 \mathrm{~min}$ should not be attributed to mergence. The particle size should sharply increase if coarsening through mergence operates. Thus the coarsening must be caused by another mechanism, Ostwald ripening. Ostwald ripening operates through the dissolution of small particles and the growth of large particles [26]. That is to say, the particle coarsening is achieved through atom diffusion and the resulting coarsening rate should be milder than that from mergence. The variation of particle size with heating time should obey the formula $D_{(t)}{ }^{3}-D_{(0)}{ }^{3}=K t$, where $D_{(t)}$ is the average particle size at time t, $D_{(0)}$ is the initial particle size, and $\mathrm{K}$ is the coarsening rate constant [26], if the coarsening results from Ostwald ripening. However, Figure 11 indicates that the coarsening during the period from 25 to 60 min does not obey this regime. The alumina layer will hinder the diffusion ability of atoms, which should inhibit the Ostwald ripening. However, the oxide film can be effectively broken in some local zones due to the relative sliding and deformation of the powders during cold pressing, and local fresh contact surfaces between powders can be obtained [27]. As the temperature in the specimen rises, these contact zones melt to form liquid paths. So the atom diffusion among the particles may be accelerated from these sites. According to this standpoint, slight coarsening results from Ostwald ripening. However, compared with other as-casting materials [28], the coarsening rate of the primary particles after the semi-solid systems reach a solid/liquid equilibrium state is quite slow, even if the atoms' diffusion ability through the local fresh paths among particles is enhanced to a certain degree. More importantly, it can be supposed that one powder in the as-pressed microstructure will basically evolve into one spheroidal particle in the semisolid microstructure. Thus the final coarsening after 30 min results from the impeditive Ostwald ripening. 


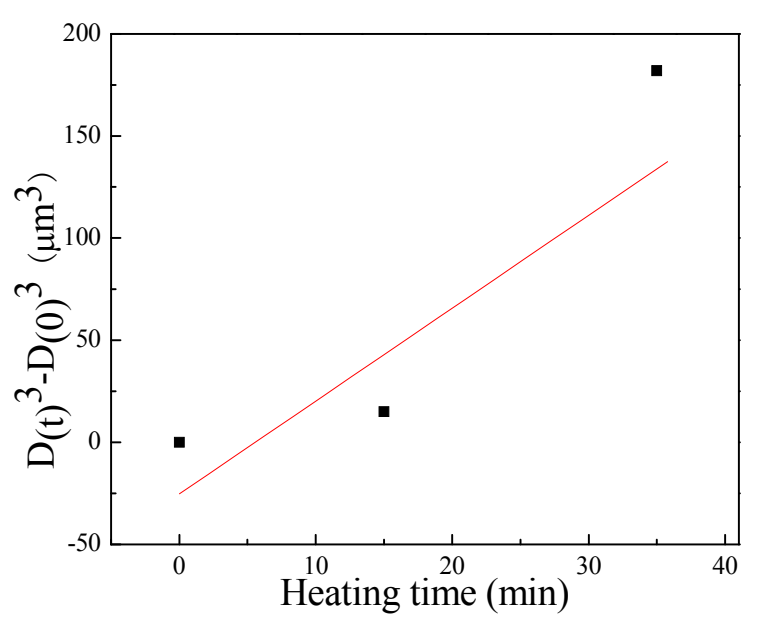

Figure 11. Cube of the primary particle size versus heating time, taking $25 \mathrm{~min}$ as starting time, $t=0$.

Based on the above discussion, the microstructural evolution of the 2024 bulk alloy can be divided into three stages: the initial rapid coarsening of the fine grains due to the dissolution of eutectic $\theta$ phase (0-3 $\mathrm{min}$ ), the formation of continuous liquid layer on the primary particle surface owing to the partial melting of the particles (3-30 $\mathrm{min}$ ), and the final coarsening attributed to the influenced Ostwald ripening (30-60 min). The coarsening rate of the particles is so slow that one powder basically evolves into one spheroidal particle in the semisolid microstructure.

\subsection{Phase Transformations during Partial Remelting}

As discussed above, the main event occurring during the heating period of $0-3 \min$ is the coarsening of the fine grains within the powders due to the dissolution of the $\mathrm{Cu}$-rich $\theta$ phase towards the $\alpha$-Al phase. In view of phase transformation, this process can be expressed as $\theta \rightarrow \alpha$. Because of this reaction, the $\theta$ phase amount decreases (comparing the diffraction intensities of the $\theta$ phase shown in Figure 12), and the $\mathrm{Cu}$ content within the primary $\alpha$ phase increases (Table 1). Thus the initial coarsening is ascribed to the reaction of $\theta \rightarrow \alpha$.

The residual $\theta$ phase melts to form liquid pools within the particles after being heated for $3 \mathrm{~min}$ (marked by arrows in Figure 5d). The essence of this process is owed to the reverse eutectic reaction, $\theta+\alpha \rightarrow \mathrm{L}$. The $\mathrm{Cu}$ content in the liquid phase decreases due to the melting of the Al-rich $\alpha$ phase (Table 1). Moreover, Figure 5d indicates that the liquid amount is small, so the solidified $\theta$ phase derived from the formed liquid phase after being quenched is negligible and the XRD can barely detect it (Figure 12). As the heating proceeds, a continuous liquid layer forms around the particles due to the partial melting of the particles (Figures $3 \mathrm{e}$ and 5f). The melting can be expressed by the reaction of $\alpha \rightarrow \mathrm{L}$. Because the primary $\alpha$-Al phase gradually melts, the $\mathrm{Cu}$ content in the liquid phase continuously decreases (Table 1). Moreover, the $\mathrm{Cu}$ solubility in the primary phase increases as the heating temperature rises [19], leading the $\mathrm{Cu}$ content in the liquid phase to further decrease and that in the primary $\alpha$ phase to increase during the period 3-10 min (Table 1). The liquid phase can solidify into the $\alpha$ phase and eutectics $(\theta+\alpha)$ after being quenched, and the eutectic $\theta$ phase amount increases with the increase of liquid amount. So the diffraction peak of the $\theta$ phase gradually becomes intensive again as the heating time is further prolonged (comparing the diffraction intensities of the $\theta$ phase during the period of 3-10 min, shown in Figure 12). Therefore, the formation of the liquid pools within the particles 
and continuous liquid layer on the primary particle surface results from the reactions of $\theta+\alpha \rightarrow L$ and $\alpha \rightarrow$ L respectively.

Table 1. Compositions of different structures of the bulk alloy heated at $635^{\circ} \mathrm{C}$ for different durations.

\begin{tabular}{ccccc}
\hline \multirow{2}{*}{ Heating Time/Min } & Structure & Al & Composition (wt\%) & \multirow{2}{*}{ Mg } \\
\cline { 4 - 5 } 0 & & & $\mathbf{C u}$ & \\
\hline \multirow{2}{*}{1} & Primary $\alpha$ & 95.9 & 3.5 & 0.6 \\
& Eutectic $\theta$ & 70.0 & 28.5 & 1.5 \\
& Primary $\alpha$ & 94.9 & 3.9 & 1.2 \\
2 & Eutectic $\theta$ & 75.7 & 23.0 & 1.3 \\
& Primary $\alpha$ & 94.9 & 4.0 & 1.1 \\
\multirow{2}{*}{3} & Eutectic $\theta$ & 88.4 & 10.8 & 0.8 \\
& Primary $\alpha$ & 95.0 & 4.2 & 0.8 \\
\multirow{2}{*}{5} & Liquid phase & 90.8 & 8.3 & 0.9 \\
& Primary $\alpha$ & 93.9 & 4.8 & 1.3 \\
\multirow{2}{*}{10} & Liquid phase & 91.7 & 7.8 & 0.5 \\
& Primary $\alpha$ & 92.7 & 5.8 & 1.5 \\
\multirow{2}{*}{20} & Liquid phase & 95.7 & 3.7 & 0.6 \\
& Primary $\alpha$ & 94.4 & 4.6 & 1.0 \\
\multirow{2}{*}{30} & Liquid phase & 95.2 & 3.9 & 0.9 \\
& Primary $\alpha$ & 94.9 & 4.4 & 0.7 \\
& Liquid phase & 95.0 & 4.0 & 1.0 \\
\hline
\end{tabular}

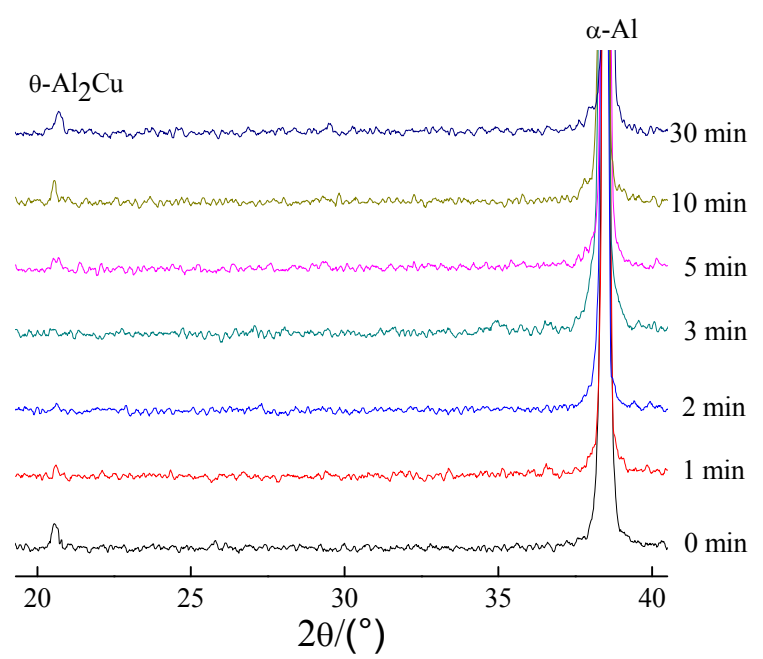

Figure 12. X-ray diffractograms of the bulk alloy heated at $635{ }^{\circ} \mathrm{C}$ for different durations and then quenched.

As the heating further proceeds, the liquid amount further increases (Figure 10). The essence of this process is still from the reaction of $\alpha \rightarrow \mathrm{L}$. However, the $\mathrm{Cu}$ solubility in the primary $\alpha$ phase decreases when the heating temperature is in the solidification interval [19]. The $\mathrm{Cu}$ content in the primary phase decreases during the 10-30 min period, while that in the liquid phase increases (Table 1).

After being heated for $30 \mathrm{~min}$, the final coarsening induced by the influenced Ostwald ripening operates. This process essentially refers to the dissolution and subsequent reprecipitation. Thus the final coarsening results from the two reverse reactions of $\alpha \rightarrow \mathrm{L}$ and $\mathrm{L} \rightarrow \alpha$. 
Therefore, it can be concluded that the microstructural evolution of the 2024 bulk alloy can be attributed to the phase transformations occurring during partial remelting. The initial coarsening is due to the reaction of $\theta \rightarrow \alpha$; the formation of the liquid pools within the particles and continuous liquid layer on the primary particle surface results from $\theta+\alpha \rightarrow L$ and $\alpha \rightarrow L$; and the final coarsening is attributed to the two reverse reactions of $\alpha \rightarrow \mathrm{L}$ and $\mathrm{L} \rightarrow \alpha$.

\subsection{Effect of Heating Temperature on Semisolid Microstructure}

Figure 13 shows the microstructures of the bulk alloy heated for $30 \mathrm{~min}$ at different temperatures. Combining with Figure $7 \mathrm{c}$, it can be seen that the primary particle size decreases and the liquid amount increases as the temperature rises. The above changes can be more clearly seen in the quantitative examinations shown in Figure 14.

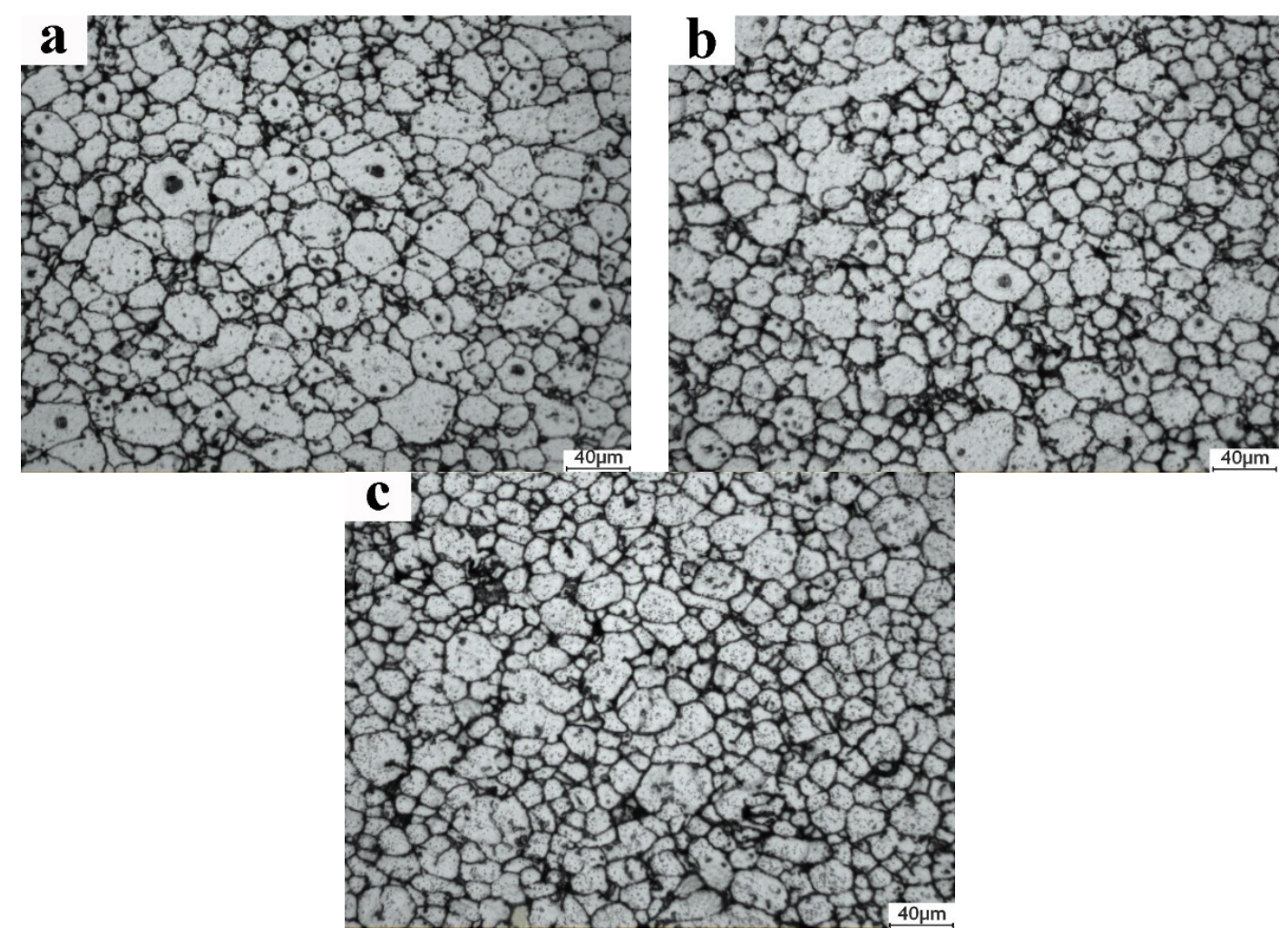

Figure 13. Micrographs of the bulk alloy heated for $30 \mathrm{~min}$ at (a) $625^{\circ} \mathrm{C}$; (b) $630{ }^{\circ} \mathrm{C}$; (c) $640{ }^{\circ} \mathrm{C}$.

As discussed above, the possibility of the merging of the primary particles is small when heated at $635{ }^{\circ} \mathrm{C}$ for different durations. For the same reason, mergence between particles is also not found at low temperature of 625 and $630{ }^{\circ} \mathrm{C}$; then the microstructure consisted of individual primary particles uniformly suspended in some liquid phase (Figure 13a,b). As the temperature rises, the liquid amount further increases due to the further partial melting of the primary particles (comparing Figures $13 \mathrm{~b}$ and $7 \mathrm{c}$ ). More of the particles can melt than at low temperature, which thus decreases the primary particle size (comparing Figure 13a,c). In addition, it can be found that the primary particles in the semisolid microstructure are always spheroidal, which should be regarded as one of the overwhelming advantages to obtaining spheroidal particles by powder thixoforming. 


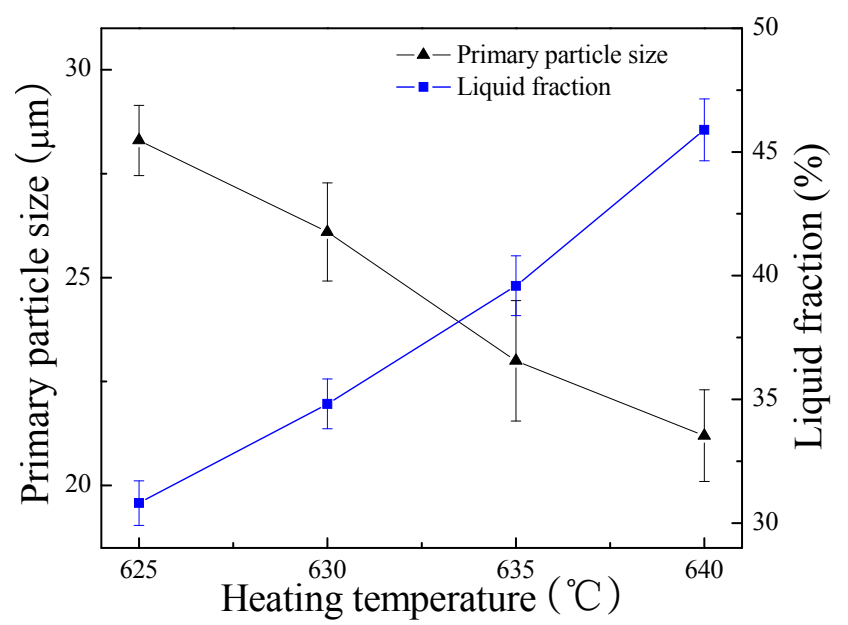

Figure 14. Variations in the primary particle size and liquid fraction with the heating temperature.

Therefore, the elevated temperature is beneficial for obtaining a semisolid ingot with small and spheroidal particles. However, it also generates a large amount of liquid phase if the temperature further rises (Figure 13c). Thus the potential of the semisolid cannot be developed until the temperature is properly controlled.

\section{Conclusions}

1. A semisolid microstructure with small and spheroidal primary particles (evolved from the original powders) can be obtained through powder thixoforming after the alloy powders are uniaxially cold-compacted and then partially remelted at $635^{\circ} \mathrm{C}$. Thus powder thixoforming is a feasible approach to producing semisolid microstructure available for thixoforming.

2. The microstructural evolution of the 2024 bulk alloy during partial remelting can be divided into three stages: the initial coarsening of the grains within powders, the formation of continuous liquid layer on the particle surface, and the final slight coarsening. The phase transformations correspond to the specific stages of the microstructural evolution. The above three stages are ascribed to the phase transformations of $\theta \rightarrow \alpha, \alpha \rightarrow L$, and $\alpha \rightarrow L$ and $L \rightarrow \alpha$, respectively.

3. The alumina on the surfaces of the alloy powders results in less active coalescence and low Ostwald ripening rate during partial remelting. The variation of the primary particle size is small. Thus it can be concluded that one spherical powder in the as-pressed microstructure evolves into one spheroidal particle with a continuous liquid layer surface in the semisolid microstructure.

4. Compared with traditional methods used to fabricate semisolid ingots, because the as-received $\mathrm{Al}_{\mathrm{p}}$ is spherical and has a powder size of $20 \mu \mathrm{m}$, and the coarsening rate of the solid particles is low, it does not need to experience a spheroidization stage to obtain small, spheroidal particles.

5. Properly raising the heating temperature is the key to obtaining an ideal semisolid microstructure.

\section{Acknowledgments}

The authors wish to express thanks for the financial support from the Basci Scientific Fund of Gansu University (Grant No. G2014-07), the Program for New Century Excellent Talents in the University of 
China (Grant No, NCET-10-0023), and Lanzhou University of Technology's Program for Hongliu Outstanding Youth.

\section{Author Contributions}

Pubo Li performed the experiments and wrote the paper under Tijun Chen's guidance, and contributed to all activities; Suqing Zhang contributed analysis tools; Pubo Li, Tijun Chen, and Renguo Guan contributed to the interpretation and discussion of results.

\section{Conflicts of Interest}

The authors declare no conflict of interest.

\section{References}

1. Fan, T.X.; Shi, Z.L.; Zhang, D.; Wu, R.J. The interfacial reaction characteristics in SiC/Al composite above liquidus during remelting. Mater. Sci. Eng. A 1998, 257, 281-286.

2. Cheng, N.P.; Zeng, S.M.; Liu, Z.Y. Preparation, microstructures and deformation behavior of $\mathrm{SiCp} / 6066 \mathrm{Al}$ composites produced by PM route. J. Mater. Process. Technol. 2008, 202, 27-40.

3. Tham, L.M.; Gupta, M.; Cheng, L. Effect of limited matrix-reinforcement interfacial reaction on enhancing the mechanical properties of Aluminium-silicon carbide composites. Acta Mater. 2001, 49, 3243-3253.

4. Kim, Y.; Lee, J.-C. Processing and interfacial bonding strength of $2014 \mathrm{Al}$ matrix composites reinforced with oxidized SiC particles. Mater. Sci. Eng. A 2006, 420, 8-12.

5. Guo, M.; Tsao, C.-Y. Tribological behavior of self-lubricating aluminium/SiC/graphite hybrid composites synthesized by the semi-solid powder-densification method. Compos. Sci. Technol. 2000, 60, 65-74.

6. Ogel, B.; Gurbuz, R. Microstructural characterization and tensile properties of hot pressed Al-SiC composites prepared from pure $\mathrm{Al}$ and $\mathrm{Cu}$ powders. Mater. Sci. Eng. A 2001, 301, 213-220.

7. Zhao, N.Q.; Nash, P.; Yang, X.J. The effect of mechanical alloying on SiC distribution and the properties of 6061 Aluminum composite. J. Mater. Process. Technol. 2005, 170, 586-592.

8. Zhou, J.; Drużdżel, A.T.; Duszczyk, J. The effect of extrusion parameters on the fretting wear resistance of Al-based composites produced via powder metallurgy. J. Mater. Sci. 1999, 34, 5089-5097.

9. Rokni, M.R.; Zarei-Hanzaki, A.; Abedi, H.R.; Haghdadi, N. Microstructure evolution and mechanical properties of backward thixoextruded 7075 Aluminum alloy. Mater. Des. 2012, 36, 557-563.

10. Wen, C.E.; Yasue, K.; Yamada, Y. Fabrication of TiAl by blended elemental powder semisolid forming. J. Mater. Sci. 2001, 36, 1741-1745.

11. Tzimas, E.; Zavaliangos, A. A comparative characterization of near-equiaxed microstructures as produced by spray casting, magnetohydrodynamic casting and the stress induced, melt activated process. Mater. Sci. Eng. A 2000, 289, 217-227. 
12. Zoqui, E.J.; Shehata, M.T.; Paes, M.; Kao, V.; Es-Sadiqi, E. Morphological evolution of SSM A356 during partial remelting. Mater. Sci. Eng. A 2002, 325, 38-53.

13. Wu, Y.F.; Kim, G.-Y.; Anderson, I.E.; Lograsso, T.A. Fabrication of Al6061 composite with high $\mathrm{SiC}$ particle loading by semi-solid powder processing. Acta Mater. 2010, 58, 4398-4405.

14. Cheng, Y.S.; Luo, S.J. Strengthening and toughening forming of $\mathrm{Al} / \mathrm{Al}_{2} \mathrm{O}_{3}$ composite in pseudo-semi-solid state. Acta Metall. Sin. 2010, 23, 21-26.

15. Luo, S.J.; Cheng, Y.S.; Wang, P.X. Pseudo-semi-solid thixoforging of cup shell with $\mathrm{Al} / \mathrm{Al}_{2} \mathrm{O}_{3}$. Trans. Nonferrous Met. Soc. China 2006, 16, 772-775.

16. Rokni, M.R.; Widener, C.A.; Crawford, G.A. Microstructural evolution of 7075 Al gas atomized powder and high-pressure cold sprayed deposition. Surf. Coat. Technol. 2014, 251, 254-263.

17. Rokni, M.R.; Widener, C.A.; Crawford, G.A.; West, M.K. An investigation into microstructure and mechanical properties of cold sprayed 7075 Al deposition. Mater. Sci. Eng. A 2015, 625, $19-27$.

18. Schueller, R.D.; Wawner, F.E.; Sachdev, A.K. Nucleation mechanism of the cubic $\sigma$ phase in squeeze-cast aluminium matrix composites. J. Mater. Sci. 1994, 29, 424-435.

19. Okamoto, H. Desk Handbook: Phase Diagrams for Binary Alloys, 1st ed.; ASM International: Materials Park, OH, USA, 2000; pp. 29-30.

20. Chen, T.J.; Jiang, X.D.; Ma, Y.; Li, Y.D.; Hao, Y. Microstructural evolution and phase transformations during partial remelting of AZ91D magnesium alloy refined by SiC. J. Alloys Compd. 2010, 497, 147-154.

21. Chen, T.J.; Jiang, X.D.; Ma, Y.; Li, Y.D.; Hao, Y. Effect of initial as-cast microstructure of AZ91D magnesium alloy on its semisolid microstructure. J. Alloys Compd. 2010, 505, 476-482.

22. Hong, T.W.; Kim, S.K.; Ha, H.S.; Kim, M.G.; Lee, D.B.; Kim, Y.J. Microstructural evolution and semisolid forming of SiC particulate reinforced AZ91HP magnesium composites. Mater. Sci. Technol. 2000, 16, 887-892.

23. Anderson, I.E.; Foley, J.C. Determining the role of surfaces and interfaces in the powder metallurgy processing of Aluminum alloy powders. Surf. Interface Anal. 2001, 31, 599-608.

24. Liu, Z.Y.; Sercombe, T.B.; Schaffer, G.B. The effect of particle shape on the sintering of Aluminum. Metall. Mater. Trans. A 2007, 38, 1351-1357.

25. Ch'ng, H.N.; Pan, J. Sintering of particles of different sizes. Acta Mater. 2007, 55, 813-824.

26. Snyder, V.A.; Alkemper, J.; Voorhees, P.W. The development of spatial correlations during Ostwald ripening: A test of theory. Acta Mater. 2000, 48, 2689-2701.

27. Xie, C.L.; Hailat, M.; Wu, X.; Newaz, G.; Taya, M.; Raju, B. Development of short fiber-reinforced NiTi/Al 6061 composite. J. Eng. Mater. Technol. 2007, 129, 69-76.

28. Jiang, H.T.; Li, M.Q. Effects of isothermal heat treatment on microstructural evolution of semisolid Al-4Cu-Mg alloy. J. Mater. Eng. Perform. 2004, 13, 488-492.

(C) 2015 by the authors; licensee MDPI, Basel, Switzerland. This article is an open access article distributed under the terms and conditions of the Creative Commons Attribution license (http://creativecommons.org/licenses/by/4.0/). 